\title{
Toward an Understanding of Development of Learning to Solve Ill-Defined Problems in an Online Context: A Multi-Year Qualitative Exploratory Study
}

\author{
Naren Peddibhotla \\ State University of New York Polytechnic Institute, Utica, NY
}

\begin{abstract}
The case study is a classic tool used in several educational programs that emphasizes solving of illdefined problems. Though it has been used in classroom-based teaching and educators have developed a rich repertoire of methods, its use in online courses presents different challenges. To explore factors that develop skills in solving ill-defined problems, I present results of a seven-year study seeking to develop tools for facilitating and assessing skills for case studies in an online graduate class. This study began with the introduction of a classroom-based case method into an online graduate class. Over the following years, I used three sources of data to make changes to the design of the course with respect to case studies: feedback from students, feedback from colleagues, and measurement of student performance. Findings suggest the following general approaches may work better in online classes involving case studies in particular, and more broadly in courses that teach solving of ill-defined problems: 1) immersion (or the use of drills) to support trial and error learning especially given the additional distractions of an online setting as compared to attending classes on campus; 2) structure to facilitate learning as it involves building skills based on absorptive capacity that students acquire from skills learned earlier; 3) social learning to enhance trial and error learning; 4) inductive learning that may be more appropriate to online teaching as compared to deductive learning; 5) provision of structure instead of participation by the instructor may encourage self-discovery of methods to solve ill-defined problems in an online context.
\end{abstract}

\section{Introduction}

There has been a trend in the last two decades that views education's role as not only imparting information but also the skills to use such information (Brandsford, Brown \& Cocking, 2000). Research has demonstrated that such expertise is built not only upon facts but also on linkages among them and an 
Toward an Understanding of Development of Learning to Solve Ill-Defined Problems in an Online Context: A Multi-Year Qualitative Exploratory Study

appreciation of how and when such facts are applicable in specific contexts (Chi, Feltovich \& Glaser, 1981; Dreyfus \& Dreyfus, 1986). An important aspect of this approach to education is the recent emphasis on "design thinking" in professional schools such as architecture, business, engineering, law, health professions and public policy (Glen, Suciu \& Baughin, 2014). Such an approach is even more relevant when teaching students to address ill-defined problems in any such domain. In contrast to "analytical thinking," which emphasizes breaking apart a context into well-defined components, design thinking stresses action to solve ill-defined problems.

To solve a problem, an individual needs to consider available information, make hypotheses, design alternative solutions, evaluate the alternatives and then take action (Simon, 1977). Ill-defined problems are those wherein "the goals themselves are complex and ill-defined, and when the very nature of the problem is successively transformed in the course of exploration" (Simon, 1986, p. 29). Given the constraints of human cognitive capacity, however, the process of solving ill-defined problems is different from dealing with semi-structured or highly structured problems (Rudolph et al. 2009). Though there are guides to improve general problem-solving skills (Cheng, 2012; Cosentino, 2013; Van Gundy, 1988), few pointers are available to direct application of such skills to a specific context.

Case studies have been used extensively in professional schools in disciplines such as business, law and public policy to provide contexts for solving a variety of ill-defined problems. A case study "imitates or simulates a real situation" (Ellet, 2007, p. 13). While they vary in length, typical case studies are about 20-25 pages long including text and pictorial material. A case study can be a vehicle to not only emphasize analytical skills but also problem-solving skills. In the former approach, a case study is employed to highlight some key concepts that are taught in a course as well as some typical or standard approaches to address the issues described in the case. Even when students in a class discuss a case study and discover relevant concepts on their own under the guidance of the instructor, the goal is to analyze and examine what is. On the other hand, in a problem-solving approach, a case study may also be used to examine what could be. The emphasis here is to design solutions to current problems based on an analysis of the case context using course concepts. This paper focuses on this latter use of case studies in learning to solve ill-defined problems.

As part of the extension of education from the classroom to the online context, case studies are also being used in online courses. However, case learning in online contexts differs in four key aspects from those in a classroom: 1) synchronicity; 2) level of formality; 3) social cues and 4) level of focus. First, due to synchronous face-to-face communication, the instructor can ask questions at the "right time" based on the current state of discussion in a classroom. On the other hand, in online asynchronous discussion forums, there is no specific "right time" as different students engage in course conversations at different times. Further, in such discussion forums a longer time is needed for an online discussion to take place, and thus the time for preparing a case is reduced as compared to an in-class context. Second, the verbal mode of communication in a classroom allows for more informality and more tolerance of making "mistakes" or making silly comments. In contrast, the written mode of communication in an online context emphasizes a formal composition of thoughts. Third, a classroom context provides more social cues, which may discourage shy participants from expressing their views as compared to the online context in which there are minimal social cues (Sproull \& Kiesler, 1986). Fourth, in case discussion in a classroom, only one student talks at a given time. In an online forum, on the other hand, there can be multiple threads of conversations making it harder to keep up with what people are saying.

Studies in a classroom setting have established the efficacy of providing structure when teaching problem solving with cases (Desiraju \& Gopinath, 2001; Siciliano \& McAleer, 1997). However, given the above differences between teaching cases online and in a classroom, we need research that helps us understand factors that facilitate problem-solving skills in an online context. This uncertainty is also reflected in the rich literature on the use of asynchronous discussion forums in online education. In 
Toward an Understanding of Development of Learning to Solve Ill-Defined Problems in an Online Context: A Multi-Year Qualitative Exploratory Study

particular, the debate among scholars and practitioners regarding the relative merits of a positivist versus constructivist approach in teaching also applies to developing skills to solve ill-defined problems in an online context. To better understand how to teach problem-solving skills using case studies in an online context, I conducted an exploratory study over a seven-year period.

The rest of the paper is organized as follows. The following section reviews the relevant literature on the use of case studies in education, the use of asynchronous discussion forums in online teaching, naturalistic decision-making and the development of expertise, and presents two research questions that I sought to address. After that, I describe how I conducted the study and my findings in the Methodology section. I conclude the paper with a discussion of the implications of my findings, limitations of the study and avenues for further research.

\section{Background Literature}

The literature has identified two broad methods of teaching with case studies (Desiraju \& Gopinath, 2001; Siciliano \& McAleer, 1997): the Harvard Case Method (HCM) and the McAleer Interactive Case Method (MICA). In HCM, there is a lesser focus on instructor-led facilitation and is oriented toward learning as a self-discovery process by students. On the other hand, MICA emphasizes focus, directs students by providing structure and views learning as achieving a specified goal. Desiraju and Gopinath (2001) found that MICA works better in a classroom setting. However, given the differences between the classroom and online context as discussed earlier, it is not clear which teaching method achieves better learning outcomes in an online setting.

Thus, the first aim of the current study was to determine which of these two methods is better suited to teaching with case studies in an online context. Further, it would help a teacher to better explore specific online teaching techniques if one understands how learning to solve ill-defined problems is achieved using case studies. Therefore a second research question was: what factors improve student learning when teaching case studies online?

A case study is a description of an organization, its employees and other stakeholders, and the situations in which they find themselves. It includes information about the organization's history, financial data, backgrounds of individuals, etc., some of which are provided in tables, charts, pictures and as quotations of conversation among individuals. Cases "don't present selected and sorted information" (Ellet, 2007, p. 13). Rather they represent scenarios that are "fluid and inevitably involve uncertainty" and that "convey a situation with all its cross currents and rough edges-including irrelevancies, sideshows, misconceptions, and little information or an overwhelming amount of it” (Ellet, 2007, p. 13). Thus, a student is asked to participate in a complex situation and recommend a course of action by not only applying what he or she has learned from the course but also by drawing upon one's own prior experience and training.

The literature on naturalistic decision-making has examined performance in situations that a case study is intended to replicate. Features that help define a naturalistic decision-making setting are time pressure, high stakes, experienced decision-makers, inadequate information (information that is missing, ambiguous or erroneous), ill-defined goals, poorly defined procedures, cue learning, context (e.g., higher level goals, stress), dynamic conditions and team coordination (Klein, 1998). But how do people learn to make decisions in such contexts? Since such settings and even case studies do not provide an individual with specific goals, he or she needs to first detect the problem(s) that need to be solved. Defining a problem is crucial as it drives the decision making process (Simon, 1977). Klein, Pliske, Crandall and Woods (2005) argue that problem detection depends on an individual's stance toward the presented context, experience, and re-conceptualization of the situation. Even after defining a problem, the 
Toward an Understanding of Development of Learning to Solve Ill-Defined Problems in an Online Context: A Multi-Year Qualitative Exploratory Study

individual needs not only the relevant skills but also needs to know how and when to apply them. How may these be learned?

Salas and Klein (2001) argue that such abilities are based on the development and sustainment of expertise. Expertise, in turn, has been shown to result from "deliberate practice” (Ericsson, Krampe \& Tesch-Romer, 1993; Horn \& Masunaga, 2006). Deliberate practice comprises activities whose main purpose is to learn and improve upon skills in a given domain. In contrast to an inherently enjoyable activity, deliberate practice is oriented toward improving performance in the individual's domain of choice. Further, such practice should comprise tasks that build upon the individual's current knowledge at a given time and should enable provision of performance feedback (Ericsson et al., 1993; Brandsford et al., 2000). Further, the educational psychology literature (e.g., Klein and Weitzenfeld, 1978) has presented frameworks for improving skills in solving ill-defined problems. However, the questions remains, "how may such approaches be implemented in an online context?"

Schwartz (2014) discusses some challenges with providing such practice and building upon existing knowledge in an online context. For example, he notes the lack of visual cues from a student for an instructor to assess whether specific course content is useful based on the student's current knowledge. Further, he presents five observations regarding challenges for student learning in online contexts: 1) hierarchically ordered nature of knowledge; 2) the importance of experience in understanding a subject; 3) the value of practice in gaining that experience; 4) the need for timely feedback; and 5) the contextsensitive nature of understanding. In order to understand how students may learn to perform well in case study analysis in an online environment, one therefore needs to examine specific tasks that build basic skills and ultimately develop their expertise in an online context.

Asynchronous forums are commonly employed in online courses in general, and are the predominant method for conducting class discussions in online formats. A vast literature has not only described various methods for conducting such discussions but also the relative efficacy of some techniques versus others (e.g., Bernard et al., 2009; Pelz, 2011). Some have studied the use of discussion forums from the perspective of the difficulties students face in learning online (e.g., Boston et al., 2011; Meyer \& McNeal., 2012). Others have focused on the challenges that instructors face in teaching online using discussion forums (e.g., Burkle and Cleveland-Innes, 2014; York and Richardson, 2013). The literature also discusses two major approaches used in online courses: "positivist” (e.g., Elias \& Merriam, 2005) and "constructivist" (e.g., Vygotsky, 1978). These two approaches attempt to address the challenges with respect to online learning and teaching in different ways. The positivist approach views teaching as imparting knowledge based on course objectives, often termed as the "sage on the stage" approach. The instructor defines the students' goals and adjusts his or her attempts to transfer knowledge based on his or her average assessment of the knowledge possessed by the group of students. An example of this perspective is the "acquisition model" of teaching (Sfard, 1998). The constructivist approach, on the other hand, lets students discover knowledge by themselves based on discussions with other students and under the guidance of the instructor - "the guide on the side" approach. The students are allowed to explore knowledge based on their individual goals. This method is manifested in well-known frameworks in both in-class contexts (e.g., see Laurillard (2002) for the teacher as a facilitator; see Sfard (1998) for the participation model) and online contexts (e.g., see Garrison et al. (2000) for the Community of Inquiry model; see Collison et al. (2000) for the Inquiry in Dialog model). In many ways, these approaches respectively mirror the MICA and HCM methods described above for teaching with case studies. Further, studies that have examined the effectiveness of student learning in online education have been conducted in structured contexts where one can compare a student's learning with an absolute standard-for example, for the theory of evolution in biology, see Ming \& Baumer (2012); for mathematics, see Bliss \& Lawrence (2010). Even where scenarios have been used-e.g., abnormal psychology (Pelz, 2011), military scenarios (LaVoie et al., 2012), etc.- - there is a set of standards based on the collective expertise of experienced individuals against which the extent of student learning is measured. These studies have 
Toward an Understanding of Development of Learning to Solve Ill-Defined Problems in an Online Context: A Multi-Year Qualitative Exploratory Study

not examined how to facilitate student problem-solving skills in domains wherein there is no best answer. Thus, we return to our original research question: which methods are appropriate in an online context for learning problem-solving skills for ill-defined problems?

I next describe the study in which I explored various methods of designing and supporting activities that provide deliberate practice to students in order to learn the skills for solving ill-defined problems.

\section{Methodology and Results}

I conducted the current study between 2007-2014 at a small-sized university in the Northeastern region of the United States. Students in two graduate programs (MBA and MS) took the required course on management information systems (MIS) in which the case study was the major method of demonstrating the application of concepts to various organizational situations. The number of students enrolled in this course online varied across the fourteen semesters: from 9 to 23 enrollees in the MBA program; from 2 to 20 students in the MS program.

Within the course, a case study document would describe a set of problems that employees in a specific organization were facing at a certain point in time. The description contained about 10-15 pages of text and about 7-10 pages of exhibits. The text contained facts about the organization, past and contemporary narratives about events, and quotes from various employees. The exhibits comprised tables, figures, photos, etc., that provided information to supplement the text in the case. Examples of such cases are available in Ellet (2007) and on websites of case publishers such as Harvard Business School Publishing (http://hbsp.harvard.edu/), Ivey Publishing (https://www.iveycases.com/), Darden Publishing (http://store.darden.virginia.edu/), etc.

The MIS course consisted of five modules, each three weeks in length. One case was assigned to each module based on the theme of that module. In each module, students were required to submit their individual case assignment by the end of the module. Table 1 lists the components that a student was required to include in his or her assignment. Each module also had a discussion forum in which the students and instructor participated to discuss various aspects of the case. I graded each student case assignment anonymously as the Word document that the student submitted could be identified only by his or her student ID number. This ensured an unbiased evaluation based on the content alone and not on the characteristics of the student submitting the assignment. Points for each case assignment component are listed in Table 1. I gave partial credit for each component based on a grading rubric (available on request from the author of this paper) that I distributed to students at the beginning of the semester. The total points a student earned was the sum of the points earned on the individual components.

For assessing student performance for the purpose of this study, however, I counted the number of components on which a student earned full points for those components. Component \# 1 (identification of problems) asked the student to list some of the problems presented in a case. It involved a replication of some material from the case as compared to the student's analysis as reflected in the remaining components of the assignment. Therefore, I considered only components \# 2, 3, 4, 5 and 6 in Table 1 for evaluating student performance for the purpose of the current study. If a student received full points on at least four out of these five components (i.e., $80 \%$ achievement), I considered him or her as having met the expectation for a good case analysis. It is possible for a student to receive an $80 \%$ score based on the grading rubric I used but not receive an $80 \%$ score based on the rating scheme used in the current study. By using a different rating scheme in this study as compared to the one used for evaluating the student in a given course for the purpose of assigning grades, I attempted to remove any potential bias on my part which would potentially lead to inflating student scores for this study. 
Table 1: Case assignment components

\begin{tabular}{|l|l|l|}
\hline S. No. & Case component & Points \\
\hline 1 & Identification of problems & 2 \\
\hline 2 & Importance of main problem & 1 \\
\hline 3 & Key stakeholders & 1 \\
\hline 4 & Causes of the main problem & 2 \\
\hline 5 & Alternative solutions to the main problem & 2 \\
\hline 6 & Recommendation to address the main problem & 2 \\
\hline
\end{tabular}

I next report the methods that I used to teach problem solving using case studies during each time period of the study as well as the results that informed new methods or changes I adopted in subsequent time periods. The time periods varied from one semester to six semesters.

\section{Semester 1}

Action: I began this study with the introduction of the classroom-based HCM case method into the online graduate class. Following the classroom-based structure of HCM, I first asked students to prepare their case analyses individually and submit their case essays before formally discussing it with other students in the class. The specification of required components of a case analysis and the points for each component (Table 1) was the student's guide. After submission of their case essays, I provided the class with access to a discussion forum in which they could submit posts with their thoughts on any aspect of the case they found interesting. For both the case essay assignment and the discussion, I provided pointers for the discussion in the form of suggested questions that they may wish to consider. During the discussion, I asked questions about what a student saw going on in the case and prodded them to justify their claims. Otherwise, the students were free to conduct the discussion as they wanted. I evaluated students only based on the number of discussion posts they submitted. The expectation was that sharing what they had written in their individual essays would enable them to learn from the thoughts of other students and improve their own analyses for the next case assignment.

Results: Many students expressed unfamiliarity with the case study method and an uneasiness with the lack of structure in the case discussions. Even with the structure of the case analysis essay assignment specification, students felt unsure about charting their own path in terms of focusing on a problem of their choice and solving it. A faculty colleague suggested that I use the data on student performance on individual components of the case assignment to develop changes to my teaching in upcoming semesters. Less than $40 \%$ of students' case analyses met or exceeded the performance expectation (Tables 2 and 3).

\section{Semesters $2 \& 3$}

Action: To address the lack of familiarity with the case study methodology, I focused on exposing students to a form of learning that was new to them. I assigned some chapters from The Case Study Handbook (Ellet, 2007) as required reading at the beginning of the semester. This book contains guidance on making persuasive arguments and also on writing and discussing cases. I also provided additional guidance in my lecture notes for the first module of the course. Further, I offered students the option to submit work on a non-graded practice case from The Case Study Handbook at the beginning of the course prior to the submission of graded assignments. Finally, to encourage making connections between the case and the course concepts in a given module, I also introduced a second discussion forum focused on the assigned reading. 
Results: The additional reading material reduced student anxiety about case studies and provided students with pointers about making logical arguments in general. However, students were not able to demonstrate they could apply those lessons to specific cases in the course. Further, only a small percentage of students attempted the practice case to develop their skills as the task was optional and did not contribute to the course grade. The percentage of students who met or exceeded the expected performance criteria decreased (Tables 2 and 3).

\section{Semester 4}

Action: After seeing that students found it difficult to apply general lessons to specific case assignments and that they did not want to spend additional effort on non-graded work, I changed my approach by providing actionable advice on specific aspects of case analysis. Thus, I discontinued the use of the non-graded practice case. Instead, I supplemented The Case Study Handbook and lecture notes on case analysis with a guide for students listing the dos and don'ts for case write-ups, case discussions and reading discussions. Based on the suggestion of a faculty colleague, this list of dos and don'ts was intended to replicate the tool of a study guide used by many instructors in their courses.

Results: The students found the list of dos and don'ts to be also too general despite its actionable advice in the context of case analysis. There was no change in the percentage of students who met or exceeded the expected performance criteria for case analysis (Tables 2 and 3).

\section{Semesters 5 and 6:}

Action: Since the course already provided a textbook and lecture notes on case analysis, I removed the list of dos and don'ts that only offered similar general advice. Instead, I turned my focus to practicing specific cases for graded work. First, I provided students with the grading rubric used to evaluate their assignments. This rubric included the partial credit assigned for various components of the case essay and common shortcomings that I had observed in student work in prior semesters. This placed the "dos and don'ts" within the context of points earned for their individual work. Second, I changed the due date of the individual case analysis assignment to a date after the students participated in the case discussion forum. This allowed them the opportunity to bounce off thoughts, issues and ideas with other students before the submission of the final case write-up assignment. The intention was to enable practice on case analysis in a specific case in the discussion before submission of the graded assignment. Third, I changed the grading for the case study in Module 1 to a simple "satisfactory / unsatisfactory" scale. A student earning more than $50 \%$ of the points received full points, whereas a student earning less than $50 \%$ and more than 0 earned $50 \%$ of the points. The objective was to change the module 1 case study to a practice case by reducing the stress associated with doing well. Fourth, I shared examples of case assignments submitted by students in previous semesters and examples from the current semester of assignments which earned full points under the normal grading scheme. The first two changes were based on student feedback. The third and fourth were based on suggestions from faculty colleagues.

Results: The students liked the opportunity to discuss the case with others in the class before the submission of their individual write-ups. It helped them to read other viewpoints on a given case and learn from one another. They also appreciated the examples of write-ups that earned full points as models for their own work. However, their performance on the write-ups did not show any improvement compared to the previous semester (Tables 2 and 3).

\section{Semesters 7-12}

Action: The results in the previous semesters suggested that an approach aligned with the MICA method may be more appropriate as compared to the HCM. To provide explicit direction, I required 
students to use specific example organizations (from one's own work experience or sources such as Business Week, Wall Street Journal) in the discussion of the assigned reading material. This was intended to help students apply the concepts from the assigned reading material to specific contexts, similar to what they needed to do for the case analysis. Further, I increased my participation in the discussions on the assigned reading and the case in order to point students toward various aspects of case analysis. Based on a suggestion from a faculty colleague, I also offered students who received below $80 \%$ of the points the opportunity to resubmit their work and address my feedback to them. This was intended to focus attention on the elements of case analysis and provide additional practice to such students.

Results: The use of specific examples by various students in the reading discussion forum provided a variety of contexts. Within these contexts, the students were able to better focus on various aspect of case analysis based on pointers that I provided with my questions and comments in the discussion forums. Further, while it involved additional work for them, students who needed additional guidance on case analysis resubmitted their work after focusing on those aspects in which they had difficulty. The average case analysis performance improved as compared to the previous semester, and more students were able to demonstrate their improved skills. However, student performance was still below that of students in the first two time periods of this study (Tables 2 and 3).

Table 2

\begin{tabular}{|c|c|c|c|}
\hline $\begin{array}{l}\text { Measure / } \\
\text { Semester }\end{array}$ & Number of students & $\begin{array}{l}\text { Average percentage of } \\
\text { case assignments that } \\
\text { met or exceeded criteria } \\
(\%)\end{array}$ & $\begin{array}{l}\text { Maximum percentage of } \\
\text { case assignments that } \\
\text { met or exceeded criteria } \\
\text { for a given case } \\
\text { assignment (\%) }\end{array}$ \\
\hline 1 & 11 & 36.84 & 50 \\
\hline 2 & 14 & 54.29 & 78.57 \\
\hline 3 & 13 & 16.67 & 38.46 \\
\hline 4 & 15 & 17.95 & 26.67 \\
\hline 5 & 9 & 24.49 & 33.33 \\
\hline 6 & 8 & 40.63 & 50 \\
\hline 7 & 22 & 19.09 & 36.36 \\
\hline 8 & 21 & 33.33 & 47.62 \\
\hline 9 & 14 & 37.14 & 57.14 \\
\hline 10 & 14 & 42.86 & 57.14 \\
\hline 11 & 14 & 32.86 & 42.86 \\
\hline 12 & 21 & 36.19 & 52.38 \\
\hline 13 & 23 & 57.39 & 73.91 \\
\hline 14 & 17 & 51.76 & 58.82 \\
\hline
\end{tabular}

Case analysis performance of online students - MBA

\section{Semesters 13-14}

Action: Encouraged by the improvement of performance scores on students' case analyses, I further extended the use of the MICA approach by directing students to specific elements of case analysis. I changed the assignments for participation in the reading discussion and case discussion forums to emphasize identification of a problem/issue in a specific organization, identification of causes, and the presentation of solutions. Students were thus required to submit their posts based on a prescribed structure that covered each of these case analysis components (Table 1). Further, I replaced The Case Study Handbook that I had introduced in Semester 2 with a textbook by Austin, Nolan and O'Donnell (2009). This textbook provides a context of a company dealing with problems in information technology 
management across all course modules. This enabled students to apply course concepts from assigned articles throughout the course to a shared context. I continued to use The Case Study Handbook as an optional textbook. Finally, I also asked students to read the discussion posts by different sets of specific students in each course module and required them to grade those students based on a rubric that granted credit for addressing the components of the case assignment as related to the organizations included in the case study as well as other organizations from the textbook, assigned readings, and other sources.

Results: Not only was student performance noticeably better than the previous time period, it was also the best that I had seen during the entire study in the past seven years (Tables 2 and 3).

Table 3

\begin{tabular}{|l|l|l|l|}
$\begin{array}{l}\text { Measure / } \\
\text { Semester }\end{array}$ & Number of students & $\begin{array}{l}\text { Average percentage of } \\
\text { case assignments that } \\
\text { met or exceeded criteria } \\
(\%)\end{array}$ & $\begin{array}{l}\text { Maximum percentage of } \\
\text { case assignments that } \\
\text { met or exceeded criteria } \\
\text { for a given case } \\
\text { assignment (\%) }\end{array}$ \\
\hline 1 & 2 & 30 & 50 \\
\hline 2 & 8 & 50 & 62.50 \\
\hline 3 & 6 & 16.67 & 33.33 \\
\hline 4 & 5 & 20 & 60 \\
\hline 5 & 9 & 26.67 & 44.44 \\
\hline 6 & 8 & 28.13 & 37.50 \\
\hline 7 & 17 & 12.94 & 17.65 \\
\hline 8 & 7 & 18.42 & 50 \\
\hline 9 & 14 & 30 & 35.71 \\
\hline 10 & 10 & 58 & 70 \\
\hline 11 & 15 & 26.67 & 40 \\
\hline 12 & 19 & 26.32 & 42.11 \\
\hline 13 & 7 & 54.29 & 71.43 \\
\hline 14 & 20 & 43 & 55 \\
\hline
\end{tabular}

Case analysis performance of online students - MS

\section{Discussion}

This study began with the introduction of the classroom-based HCM case method into an online graduate class. Over the following seven years, I used three sources of data to make changes to the design of the course with respect to case studies: feedback from students, feedback from colleagues, and student performance data.

Based on the revisions to the design of the online course, I am using the following methods to facilitate case analysis skills: 1) discussion assignment on reading material; 2) discussion assignment on a case before submission of case write-up; 3) provision of examples of case write-ups of students who received perfect scores; 4) gradebook feedback and visual indicators of performance throughout the semester; 5) requirement that students use the context of a specific example organization in their discussions; 6) encouragement to students to re-submit case analyses for partial additional credit; 7) provision of context of a specific company throughout the course; and 8) requirement of a focus on problems, causes, and solutions. 
I added the following features during the study but later withdrew them as they did not seem to facilitate student learning of case analysis: 1 ) requirement to read a case study textbook; 2) lectures on case analysis; 3) practice assignments using contexts outside the course subject; 4) provision of a detailed list of dos and don'ts; and 5) intensive instructor participation in case discussions.

The results suggest that having more structure, which is the hallmark of the MICA method, is better than the less-structured HCM for improving case analysis skills in an online environment. The unstructured process that is characteristic of HCM assumes that students will learn by engaging with the case contexts based on pointers provided by the instructor. What this study shows within an online context, however, is that case study assignments that provide structure that guide students to essential case analysis components improve their case analysis skills far better. This result affirms what Desiraju and Gopinath (2001) found in their study of case studies in a classroom context.

The MICA method, however, needs to be modified for an online environment. Given that the online environment involves reading and writing thoughts on the case, the use of a structure within the title and body of posts in the discussion forum seems to facilitate thinking about the essential case analysis components. Further, posts in an asynchronous discussion forum may not be read by the instructor immediately after they are submitted. Hence, the posts may require identification of specific problems, causes and solutions (e.g., as bullet points, paragraphs) for the benefit of both the student and other participants.

Beyond the relevance of the HCM vs. MICA methods of conducting case discussions, the results of my study suggest some broader guidance for teaching and learning in an online environment. First, the lack of cues in communication among the instructor and students calls for the use of structured communication that provides such cues in written content. Student performance in my course improved significantly after I asked students to organize their discussion posts based on a prescribed structure. This enabled them to convey their thoughts more explicitly and helped other students better understand the content in those posts. Those cues also served to define the sub-goals that students needed to address within their overall goal of recommending a course of action for the organization being discussed in a particular case study. These methods thus address two of the challenges, lack of cues and undefined goals, which are inherent in contexts of naturalistic decision making (Klein, 1998). Second, these methods also address a third aspect of naturalistic decision-making, which is the need for experience in order to achieve excellence in performance, by providing practice. Prior research in learning (Brandsford et al., 2000; Ericsson, 1993) indicates that knowledge is organized as a hierarchy and that practice enables an individual to build upon previously learned skills to progress toward achieving expertise. To simulate practice in my course, students repeatedly worked on identifying problems and causes and designing solutions. Within a given Module, they contributed their thoughts on these aspects of case analysis when they submitted posts to the discussion forums focused on the assigned reading and the Case respectively. They also worked on these skills by evaluating the contributions of other students in discussion forums. Further, students who received less than $80 \%$ of the maximum points were invited to revise their work based on feedback and submit it again, thus gaining additional practice. Lastly, they gained practice by following the same pattern of assignments across the five Modules in the course by working with different case studies and reading materials in each Module. Overall, this study offers some specific methods for teaching case analysis skills in order to address some of the challenges noted by Schwartz (2014) with student learning in an online context.

Further, my study suggests an alternative lens to view the ongoing debate about the positivist vs. constructivist approaches to teaching in general, and in an online context in particular. The findings from prior research on human learning may be summarized as shown in Figure 1 (next page). On the one hand, we have a student who comes to class with existing knowledge and who has goals specific to him or her with respect to attaining new knowledge. On the other hand, the student's instructor estimates the current 
knowledge the student has mastered and guides the student toward knowledge goals that the instructor believes are relevant. The student has obtained knowledge from prior education and experience and is oriented toward achieving knowledge goals based on objectives derived from personal interests related to one's career or otherwise. The instructor strives to assess the student's current knowledge based on performance in class and presents new knowledge that is not only related to that existing knowledge but also develops skills that the instructor believes are needed by other courses in the program, potential employers, and the community at large. The positivist approach involves the instructor playing a more dominant role imparting knowledge based on an estimated average of current knowledge possessed by students in the class and an assessment of what he or she believes is important for the students (Sfard, 1998). On the other hand, the constructivist approach potentially allows for students to add to their own individual knowledge foundations based on their own interests. A common implementation of this approach in online education is the "Community of Inquiry" framework (Garrison et al., 2000). A third approach that educators follow has been termed the "ecological approach." Viewed from this perspective, learning is "the education of intention and attention" (Effken et al., 2010, p. 42). By immersing the student in a situation that simulates a real scenario and assessing student performance, the instructor encourages students to develop goals that are more aligned with future demands on them from employers and the community. By focusing less on interaction with others and more with the scenarios, students assess the state of their own knowledge and thus what they need to be able to address problems they encounter in the scenarios. This approach mirrors the one advocated by the literature on Naturalistic Decision Making (Klein, 1998). The ecological approach may thus be more appropriate for teaching skills in solving ill-defined problems, as compared to the positivist and constructivist approaches that may be more suitable for other domains.

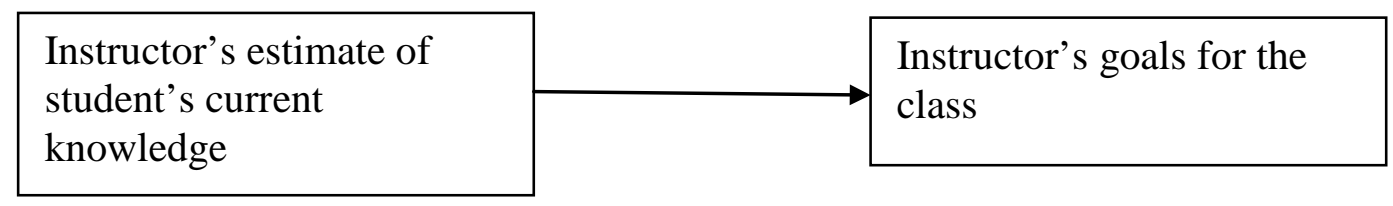

(a): Positivist approach

\begin{tabular}{|l|l|}
\hline $\begin{array}{l}\text { Student's estimate of own } \\
\text { current knowledge }\end{array}$ & Student's goals \\
\cline { 2 - 3 }
\end{tabular}

(b): Constructivist approach

Real-life contexts curated by instructor

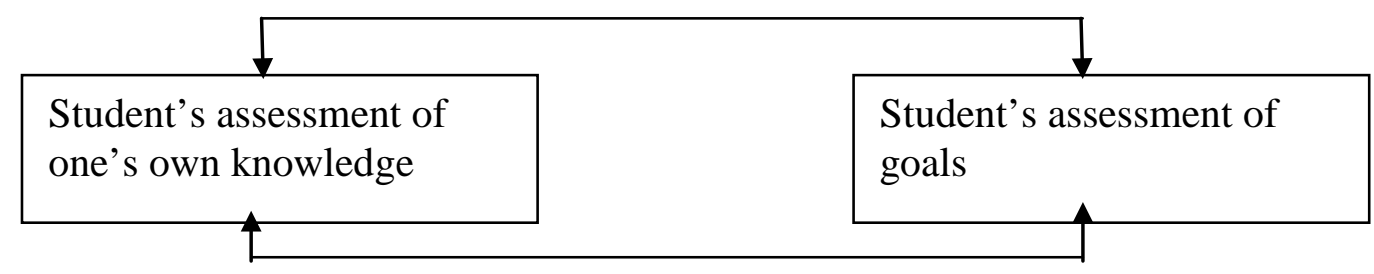

(c): Ecological approach

Figure 1: Three approaches to teaching solving of ill-defined problems 


\section{Limitations}

I acknowledge some limitations of this exploratory study. First, the research is based on data gathered from student performance in a single course at one university. Factors such as course content and student background were therefore specific to the particular context and were not examined across multiple sites. Second, since multiple teaching methods were introduced, modified and withdrawn over the seven-year period, the effect of each individual method could not be inferred as accurately as would be possible using a more controlled study. Third, performance on case analysis was measured using a grading rubric that was modified for the purpose of this study. Despite the difference in this study's measure as compared to the score used for grading in the course, not all personal bias may have been eliminated. Nevertheless, these limitations and the above lessons suggest avenues for future research. For example, in order to understand the usefulness of specific teaching methods in an online context, we need to conduct experiments that can isolate their individual effects. Additional work is also required to observe the efficacy of different approaches in improving case analysis skills across time.

\section{Conclusion}

Overall, this paper reports on an initial study of teaching methods that facilitate or, in contrast, do not develop skills in solving ill-defined problems in an online context. I identified factors that may also be relevant in a classroom setting and that are consistent with prior research on human learning. However, this paper also highlights those teaching methods that may be especially salient when teaching problem solving via case studies in online contexts.

The relative efficacy of these teaching methods suggest the following general approaches may work better in online classes involving case analysis in particular and more broadly in courses that employ problem-solving: 1) immersion (or the use of drills) to support trial and error learning especially given the additional distractions of an online setting as compared to attending classes on campus; 2) structure to facilitate learning as it involves building skills based on absorptive capacity that students acquire from skills learned earlier; 3) social learning to enhance trial and error learning; 4) inductive learning that may be more appropriate to online teaching as compared to deductive learning; and 5) provision of structure instead of participation by the instructor may encourage self-discovery of methods to solve ill-defined problems in an online context.

\section{Acknowledgments}

I would like to thank my colleagues Dr. Lisa Berardino and Dr. Robert Edgell, for feedback on an earlier version of this paper that helped improve its quality. I also acknowledge the comments and suggestions from participants at the twenty-third Conference on Instruction and Technology (CIT) in 2014 at Cornell University, Ithaca, NY, and seminar participants at the SUNY Polytechnic Institute where I had presented work reported in this paper. Finally, I am grateful for financial support from the SUNY Polytechnic Institute.

\section{About the Author}

Naren Peddibhotla is an Assistant Professor in the Department of Business Management at the State University of New York Polytechnic Institute at Utica, New York. He has taught undergraduate and graduate courses in Management Information Systems, Innovation, Entrepreneurship, and Product Design. His research seeks to understand knowledge sharing in online contexts in four research streams: contribution behavior, knowledge sourcing behavior, assessment of expertise and knowledge transfer in 
Toward an Understanding of Development of Learning to Solve Ill-Defined Problems in an Online Context:

A Multi-Year Qualitative Exploratory Study

online learning in higher education. His work has been published or is forthcoming in these journals: Electronic Commerce Research and Applications, Electronic Markets, Organization Studies, and the Online Learning Journal. He has presented his research at forums such as the Academy of Management annual meeting (AOM), the Americas Conference on Information Systems (AMCIS), the Behavioral Decision Research in Management conference (BDRM), the Summer Institute of the Consortium for the Science of Sociotechnical Systems (CSST) and the Decision Science Institute annual meeting (DSI).

\section{References}

Austin, R. D., Nolan, R. L., \& O’Donnell, S. (2009) The adventures of an IT leader. Boston, MA: Harvard Business School Press.

Bernard, R. M., Abrami, P. C., Borokhovski, E., Wade, C. A., Tamim, R., Surkes, M. A., \& Bethel, E. C. (2009) A meta-analysis of three types of interaction treatments in distance education. Review of Educational Research, 79(3), 1243-1289.

Bliss, C. A. \& Lawrence, B. (2010) From posts to patterns: a metric to characterize discussion board activity in online courses. Journal of Asynchronous Learning Networks, 13(2), 15-32.

Boston, W., Ice, P., Diaz, S. R., Richardson, J., Gibson, A. M. \& Swan, K. (2011) An exploration of the relationship between indicators of the community of inquiry framework and retention in online programs. Journal of Asynchronous Learning Networks, 14(1), 67-83.

Brandsford, J. D., Brown, A. L., Cocking, R. R. (Eds.) (2000) How people learn: brain, mind, experience and school. Washington, DC: National Academy Press.

Burkle, M. \& Cleveland-Innes, M. (2014) Defining the role adjustment profile of learners and instructors online. Journal of Asynchronous Learning Networks, 17(1) 73-87.

Cheng, V. (2012) Case interview secrets: a former McKinsey Interviewer reveals how to get multiple job offers in consulting. Seattle: Innovation Press

Chi, M. T. H., Feltovich, P. J., \& Glaser, R. (1981) Categorization and representation of physics problems by experts and notices. Cognitive Science, 5, 121-152

Collison, G., Elbaum, B., Haavind, S. \& Tinker, R. (2000) Facilitating online learning: effective strategies for moderators. Madison, WI: Atwood Publishing.

Cosentino, M. P. (2013) Case in Point: Complete Case Interview Preparation (8th Edition), Santa Barbara, CA: Burgee Press.

Desiraju, R. and C. Gopinath (2001) Encouraging participation in case discussions: a comparison of the MICA and Harvard Case Methods. Journal of Management Education, 25(4) 394-408.

Dreyfus, H. L. \& Dreyfus, S. E. (1986) Mind over machine: the power of intuition and expertise in the era of the computer. New York, NY: The Free Press.

Effken, J., McEwen, M., Vincent, D., Shea, K., Garcia-Smith, D., Kang, Y. \& Young, M. (2010) Application and evaluation of the ecological psychology approach to instructional design (EPAID). Journal of Asynchronous Learning Networks, 13(4), 41-56. 
Elias, J., \& Merriam, S. (2005) Philosophical foundations of adult education. Malabar, FL: Krieger Publishing Company.

Ellet, W. (2007) The case study handbook. Boston, MA: Harvard Business School Press

Ericsson, K. A., Krampe, R. T., \& Tesch-Romer, C. (1993) The role of deliberate practice in the acquisition of expert performance. Psychological Review, 100(3), 363-406.

Garrison, D. R., Anderson, T., \& Archer, W. (2000) Critical inquiry in a text-based environment: computer conferencing in higher education. Internet and Higher Education, 11(2), 1-14.

Glen, R., C. Suciu, C. Baughin (2014) The need for design thinking in business schools. Academy of Management Learning and Education, 13(4), 653-667.

Horn, J. \& Masunaga, H. (2006) A merging theory of expertise and intelligence. In K. A. Ericsson, N. Charness, P. J. Feltovich and R. R. Hoffman (Eds.), The Cambridge handbook of expertise and expert performance, pp. 587-611, New York, NY: Cambridge University Press.

Klein, G. (1998). Sources of power. Cambridge, MA: MIT Press

Klein, G., Pliske, R., Crandall, B., \&Woods, D. D., (2005) Problem detection. Cognition, Technology and Work, 7, 14-28.

Klein, G. A. \& Weitzenfeld, J. (1978) Improvement of skills for solving ill-defined problems. Educational Psychologist, 13, 31-41.

Laurillard, D. (2002) Rethinking university teaching. London: Routledge.

LaVoie, N., Streeter, L., Lochbaum, K., Wroblewski, D., Boyce, L., Krupnick, C., Psotka, J. (2011) Automating expertise in collaborative learning environments. Journal of Asynchronous Learning Networks, 14(4), 97-119.

Meyer, K. A. \& McNeal, L. (2012) How online faculty improve student learning productivity. Journal of Asynchronous Learning Networks, 15(3), 37-53.

Ming, N. \& Baumer, E. (2012) Using text mining to characterize online discussion facilitation. Journal of Asynchronous Learning Networks, 15(2), 71-109.

Pelz, B. (2011) (My) three principles of effective online pedagogy, Journal of Asynchronous Learning Networks, 14(1), 33-46.

Rudolph, J. W., Morrison, J. B. \& Carroll, J. S. (2009) The dynamics of action-oriented problem-solving: linking interpretation and choice. Academy of Management Review, 34(4), 733-756.

Salas, E., and G. Klein (2001). Expertise and naturalistic decision making: an overview. In E. Salas and G. Klein (Eds.), Linking expertise and naturalistic decision making, Mahwah, NJ: Lawrence Erlbaum Associates.

Schwartz, M. (2014) Khan Academy: The illusion of understanding. Journal of Asynchronous Learning Networks, 17(4). 
Sfard, A. (1998) On two metaphors for learning and the dangers of choosing just one. Educational Researcher, 27(2), 4-13.

Siciliano, J. \& McAleer, G. M. (1997) Increasing student participation in case discussions: using the MICA. Journal of Management Education, 21(2), 209-220.

Simon, H.A. (1977). The new science of management decision. Upper Saddle River, NJ: Prentice-Hall.

Simon, H.A. (1986). Report of the research briefing panel on decision making and problem solving. Washington, DC: National Academy of Sciences.

Sproull, L. \& Kiesler, S. (1986) Reducing social context cues: electronic mail in organizational communication. Management Science, 32(11), 1492-1512.

VanGundy, A. B. Jr. (1988) Techniques of structured problem solving (2nd Edition). New York, NY: Van Nostrand Reinhold.

Vygotsky, L. S. (1978) Mind and society: the development of higher mental processes. Cambridge, MA: Harvard University Press.

York, C. S. \& Richardson, J. C. (2012) Interpersonal interaction in online learning: experienced online instructors' perceptions of influencing factors. Journal of Asynchronous Learning Networks, 16(4), 83-98. 